\title{
A demographic study of patients with behavioral and neurodevelopmental disorders among children in East India
}

\author{
Papiya Khawash ${ }^{1}$, Anindita Chatterjee ${ }^{2}$, Adrita Khawash ${ }^{3}$ \\ From ${ }^{1}$ Senior Consultant and Developmental Paediatrician, ${ }^{2}$ Consultant Clinical Psychologist, Developmental Paediatrician, Child Guidance Clinic, \\ Department of Paediatrics, Peerless Hospital and B. K. Roy Research Centre, 360 Panchasayar Road, Sahid Smrity Colony, Panchasayar, Kolkata, \\ West Bengal, India, ${ }^{3}$ Junior Clinical Fellow, Department of Paediatrics, Epsom and St Helier University Hospitals NHS Trust, Wrythe Lane, Carshalton, \\ Surrey SM5 1AA, England
}

\section{ABSTRACT}

Background: The prevalence of behavioral and neurodevelopmental disorders of children in India is changing according to recent data, as more young children with these problems are now being identified. Aim: Our study aims to assess the emerging patterns of these disorders in patients attending an urban child guidance clinic in Kolkata. Method: A retrospective analysis of the demographic data of patients attending the clinic over the period of 1 year (April 2018-March 2019) was performed. Results: A significant 55.6\% of total 651 patients in our study were children with autism spectrum disorder (ASD). Children $<5$ years of age constituted a significant percentage (55.3\%) of patients attending the clinic and boys were in significantly larger numbers (74.8\%) compared to girls (25.2\%). About 52.3\% of the children came from Kolkata, 35.4\% from other districts of West Bengal, 5.4\% from other East Indian states, and 6.9\% from the neighboring country Bangladesh. Conclusion: ASD, a developmental disability of public health importance affecting both child and family, has been identified in significantly large number of children in our study. This may be attributed to increased community awareness resulting in earlier identification/referral of cases; although an actual rise in incidence is also a possibility. The male bias noted in the study is ascribed to a significantly larger number of boys with ASD, behavioral issues, attention deficit hyperactivity disorder, learning disabilities, and intellectual impairment.

Key words: Child guidance clinic, Demographics, Neurodevelopmental, Behavioral

$\mathrm{T}$ he child guidance movement began as an idealistic mission in the 1920s to prevent juvenile delinquency by identifying the problem in child. By the 1930s, child guidance clinics (CGC) employed clinical teams of psychiatrists, psychologists, and social workers to treat children and adolescents with behavioral problems. In India, the first CGC was started in 1937 by Dr. Clifford Manshardt, at Tata Institute of Social Sciences in Mumbai on an experimental basis to fulfill both clinical and educational functions. As per the WHO, there should be one CGC per 1 lakh child. However, a study done by National Institute of Public Co-operation and Child Development had documented only 156 CGCs for the entire country, nearly all of them being located in big metropolitan cities [1].

Changing structure of the family and lifestyles as well as industrialization/urbanization has negatively influenced child mental health. The study on child and adolescent psychiatric disorders in urban and rural areas conducted by Indian Council

\section{Access this article online}

Received - 02 July 2021

Initial Review - 28 August 2021

Accepted - 06 September 2021

DOI: $10.32677 / \mathrm{IJCH} .2021 . v 08.109 .3027$ of Medical Research in 2001, indicated the overall prevalence of mental and behavioral disorders among children as $12.8 \%$ [1]. In a more recent study, the prevalence of neurodevelopmental disorders (NDDs) such as vision impairment, epilepsy, neuromotor impairments including cerebral palsy, hearing impairment, speech and language disorders, autism spectrum disorders (ASD), intellectual disability, attention deficit hyperactivity disorder, and learning disorders in children aged 2-9 years was estimated across five geographically diverse regions in India. The site-specific prevalence in $2-<6$ years olds ranged between $2.9-18.7 \%$ and in $6-9$-year-old children from $6.5 \%$ to $18.5 \%$. The study concluded that almost one in eight children of the age 2-9 years has at least one of the nine NDDs. Therefore, NDDs were considered as a significant public health burden for India. The current study aimed to assess the emerging patterns of behavioral and NDDs in children along with the assessment of the nature of interventional services sought and provided for these children at the clinic. We found the prevalence of ASD to be comparable to the published literature [2].

Correspondence to: Papiya Khawash, Developmental Paediatrician, Child Guidance Clinic, Department of Paediatrics, Peerless Hospital and B. K. Roy Research Centre, 360 Panchasayar Road, Sahid Smrity Colony, Panchasayar, Kolkata - 700 040, West Bengal, India. E-mail: pkhawash@gmail.com

(C) 2021 Creative Commons Attribution-NonCommercial 4.0 International License (CC BY-NC-ND 4.0). 


\section{MATERIALS AND METHODS}

Our study is a retrospective analysis of the demographic data of patients attending a CGC of urban India. The clinic is a part of a multidisciplinary hospital located in Kolkata, the largest metropolis of eastern India. It handles referral-based cases such as referrals from the attending pediatrician, worried parents, teachers, and schools showing concerns about the development or behavior of the child. The core team of the clinic consists of a developmental pediatrician, a pediatric clinical psychologist, special educators, speech and language therapists, occupational and play therapists, and physiotherapists. Consultation and referral services include pediatric neurologist, audiologist, clinical geneticist, and psychiatrist. Apart from consultations, the clinic provides psychometric evaluations and assessments to help provide classroom accommodations and modifications in school. The demographic data of patients attending the CGC and presenting to the core team of CGC over the period of a year (April 2018-March 2019) were collected and analyzed while excluding the referral services.

The study was reviewed and approved by the Institutional Ethics Committee. Informed consent was not required because of the retrospective nature of this study; however, all precautions were taken to protect patient confidentiality and identity.

\section{RESULTS}

No significant difference in the month-wise distribution of the cases was noted. About $52.3 \%$ of patients attending the clinic were from Kolkata city; $35.4 \%$ from other West Bengal districts; $5.4 \%$ of patients were from other eastern states; and $6.9 \%$ of patients were from the neighboring country of Bangladesh. A total of 651 patients attended the clinic throughout the year, of which $508(78 \%)$ were new patients and $143(22 \%)$ were follow-up patients. Of the total, $360(55.3 \%)$ were $<5$ years of age; $174(26.7 \%)$ were between 6 and 10 years; $90(13.8 \%)$ were between 11 and 15 years; 20 (3.1\%) were between 16 and 20 years; and 7 patients $(1.1 \%)$ between 21 and 25 years. Boys attended the clinic in significantly larger numbers (487 patients; $74.8 \%$ ) than girls (164 patients; $25.2 \%$ ).

Table 1 shows the prevalence of various types of behavioral disorders as recorded throughout the year. Of the neuropsychiatric problems (22 cases), depression (12 cases) was the most common, with one case each of panic attack, psychotic tendency, hallucination, psychogenic headache, psychogenic polydipsia, performance anxiety, and two cases of schizophrenia. Nonspecific behavioral issues in children (43 cases; 6.6\%) included bed-wetting, adjustment problems, anger issues, attentionseeking behavior, temper tantrums, and night terrors. The most common syndrome was Down syndrome (9 out of 17 patients), followed by Prader-Willi syndrome ( 3 cases), and single cases of other isolated rare syndromes.

Fig. 1 shows the age-wise analysis of behavioral issues. The small number of older adolescents ( $>15$ years) and young adults presented in the clinic with neuropsychiatric problems and gender
Table 1: Frequency of different type of cases throughout the year

\begin{tabular}{|c|c|c|}
\hline Diagnosis & Frequency & Percentage \\
\hline Autism spectrum disorder (ASD) & 362 & 55.6 \\
\hline Intellectual impairment & 66 & 10.1 \\
\hline Behavioral issues & 43 & 6.6 \\
\hline $\begin{array}{l}\text { Attention deficit hyperactivity disorder } \\
\text { (ADHD) }\end{array}$ & 26 & 4.0 \\
\hline Neuropsychiatric problems & 22 & 3.4 \\
\hline Learning disorder (LD) & 21 & 3.2 \\
\hline $\begin{array}{l}\text { Global developmental delay with autism } \\
\text { spectrum disorder (GDD with ASD) }\end{array}$ & 18 & 2.8 \\
\hline Syndromic child & 17 & 2.6 \\
\hline Obsessive compulsive disorder (OCD) & 12 & 1.8 \\
\hline Slow learners & 10 & 1.5 \\
\hline Generalized anxiety disorder (GAD) & 7 & 1.1 \\
\hline Global developmental delay (GDD) & 7 & 1.1 \\
\hline Gender issues & 5 & 0.8 \\
\hline Speech and articulation disorder & 5 & 0.8 \\
\hline Oppositional defiant disorder (ODD) & 5 & 0.8 \\
\hline School issues & 4 & 0.6 \\
\hline Seizure disorder & 3 & 0.5 \\
\hline Eating disorder & 2 & 0.3 \\
\hline Hearing impairment & 2 & 0.3 \\
\hline Body image issues & 1 & 0.2 \\
\hline Delinquency & 1 & 0.2 \\
\hline Internet addiction & 1 & 0.2 \\
\hline Tourette syndrome & 1 & 0.2 \\
\hline No abnormality & 10 & 1.5 \\
\hline Total & 651 & 100 \\
\hline
\end{tabular}

identity issues. Adolescents with more serious problems such as conduct disorders and drug addiction were not seen during this study period.

Of the children with ASD attending the clinic, boys were significant $(283 ; 78.18 \%)$ in numbers. Table 2 describes the gender-wise distribution of the prevalence of cases.

Children with the detected cases of behavioral disorders were attending the clinic for various interventional therapies, the distribution of which is described in Table 3.

Data on the clinical and psychometric assessment/testing tools used in the clinic were collected and analyzed. The most commonly used testing tool was childhood autism rating scale-2 (CARS-2), used for younger ( $<6$ years) or lower functioning cases of ASD while CARS-HF was used for high-functioning cases [3]. Vineland social maturity scale (VSMS) was also frequently used to assess social and adaptive competence [4]. Conner's rating scale was used for the assessment of children with ADHD [5]. For IQ assessment, testing tools used in the clinic were Wechsler Intelligence Scale for Children for ages 6-15 years [6] and WAIS (Wechsler Intelligence Scale for Adult) for $\geq 16$ years [7]. For quick review of intelligence in small children (3-15 years of age), the Seguin form board test, based on the single factor theory of intelligence, measuring speed, and accuracy, was used [8]. DST-J and S (dyslexia screening test for junior and senior) was 


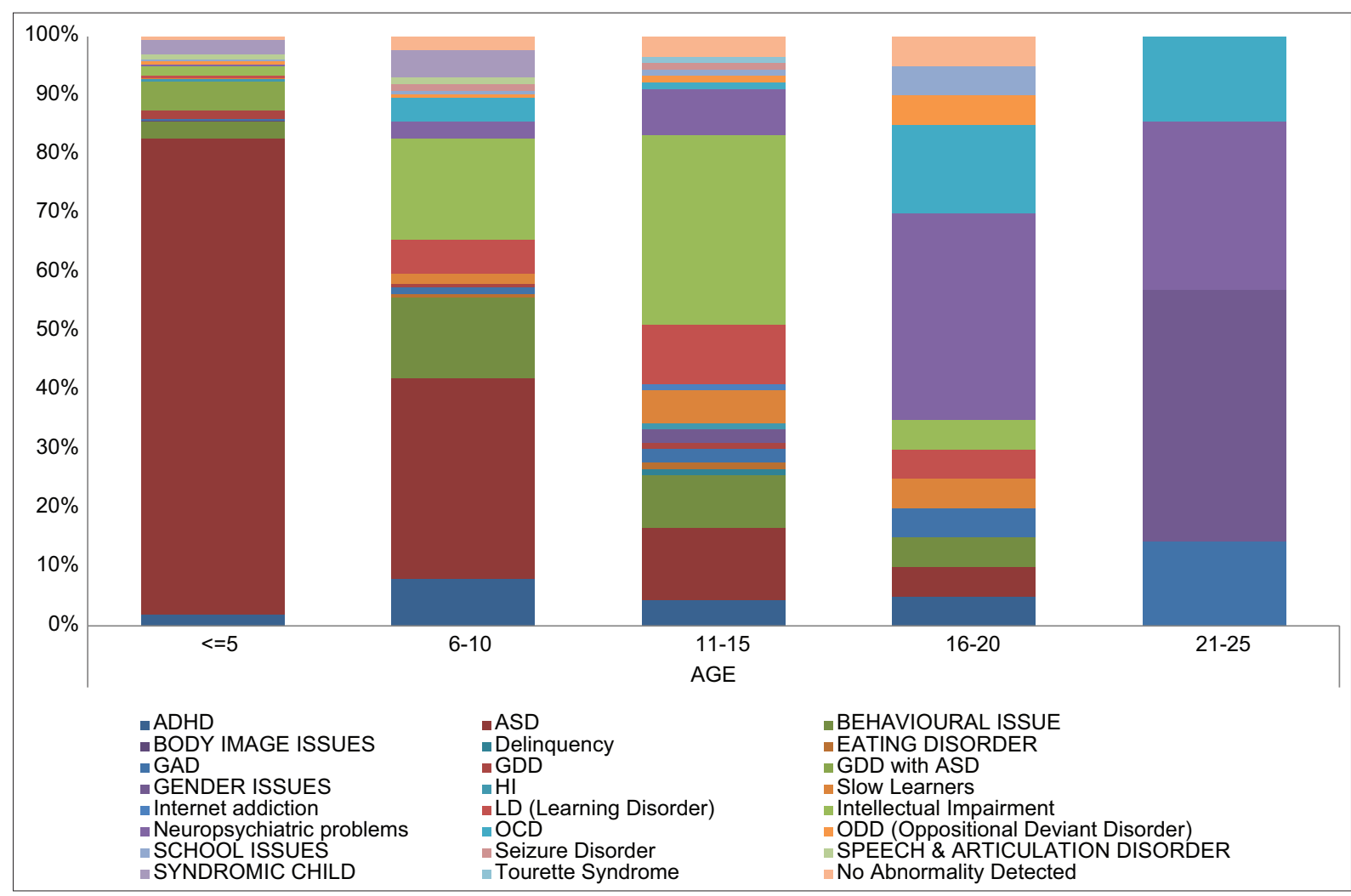

Figure 1: Age-wise distribution of cases

Table 2: Gender-wise distribution of cases

\begin{tabular}{|c|c|c|c|c|c|}
\hline Diagnosis & $\begin{array}{l}\text { Male (number } \\
\text { [percentage]) }\end{array}$ & $\begin{array}{l}\text { Female (number } \\
\text { [percentage]) }\end{array}$ & $\begin{array}{l}\text { Total (number } \\
\text { [percentage]) }\end{array}$ & $p$ value & Significance \\
\hline Attention deficit hyperactivity (ADHD) & $21(80.77)$ & $5(19.23)$ & $26(100)$ & $<0.001$ & Significant \\
\hline Autism spectrum disorder (ASD) & $283(78.18)$ & $79(21.82)$ & $362(100)$ & $<0.001$ & Significant \\
\hline Behavioral issue & $30(69.77)$ & $13(30.23)$ & $43(100)$ & $<0.001$ & Significant \\
\hline Body image issues & $0(0)$ & $1(100)$ & $1(100)$ & NA & NA \\
\hline Delinquency & $1(100)$ & $0(0)$ & $1(100)$ & NA & NA \\
\hline Eating disorder & $0(0)$ & $2(100)$ & $2(100)$ & NA & NA \\
\hline Generalized anxiety disorder (GAD) & $3(42.86)$ & $4(57.14)$ & $7(100)$ & 0.589 & Not significant \\
\hline Global developmental delay (GDD) & $7(100)$ & $0(0)$ & $7(100)$ & NA & NA \\
\hline GDD with ASD & $12(66.67)$ & $6(33.33)$ & $18(100)$ & 0.034 & Significant \\
\hline Gender issues & $3(60)$ & $2(40)$ & $5(100)$ & 0.519 & Not significant \\
\hline Hearing impaired (HI) & $2(100)$ & $0(0)$ & $2(100)$ & NA & NA \\
\hline Slow learners & $8(80)$ & $2(20)$ & $10(100)$ & 0.001 & Significant \\
\hline Internet addiction & $1(100)$ & $0(0)$ & $1(100)$ & NA & NA \\
\hline Learning disorder (LD) & $15(71.43)$ & $6(28.57)$ & $21(100)$ & 0.002 & Significant \\
\hline Intellectual impairment & $54(81.82)$ & $12(18.18)$ & $66(100)$ & $<0.001$ & Significant \\
\hline Neuropsychiatric problems & $10(45.45)$ & $12(54.55)$ & $22(100)$ & 0.545 & Not significant \\
\hline Obsessive compulsive disorder (OCD) & $7(58.33)$ & $5(41.67)$ & $12(100)$ & 0.408 & Not significant \\
\hline Oppositional defiant disorder (ODD) & $5(100)$ & $0(0)$ & $5(100)$ & NA & NA \\
\hline School issues & $1(25)$ & $3(75)$ & $4(100)$ & 0.102 & Not significant \\
\hline Seizure disorder & $3(100)$ & $0(0)$ & $3(100)$ & NA & NA \\
\hline Speech and articulation disorder & $3(60)$ & $2(40)$ & $5(100)$ & 0.519 & Not significant \\
\hline Syndromic child & $12(70.59)$ & $5(29.41)$ & $17(100)$ & 0.008 & Significant \\
\hline Tourette Syndrome & $1(100)$ & $0(0)$ & $1(100)$ & NA & NA \\
\hline No abnormality detected & $5(50)$ & $5(50)$ & $10(100)$ & 1.000 & Not significant \\
\hline
\end{tabular}


Table 3: Frequency of cases for different interventional therapies

\begin{tabular}{|c|c|c|c|}
\hline $\begin{array}{l}\text { Types of } \\
\text { therapy }\end{array}$ & Diagnosis & Frequency & Percentage \\
\hline \multirow[t]{8}{*}{$\begin{array}{l}\text { Special } \\
\text { educators }\end{array}$} & $\begin{array}{l}\text { Autism spectrum } \\
\text { disorder (ASD) }\end{array}$ & 236 & 86.8 \\
\hline & Behavioral issue & 1 & 0.4 \\
\hline & Down's syndrome & 2 & 0.7 \\
\hline & $\begin{array}{l}\text { Global developmental } \\
\text { delay (GDD) }\end{array}$ & 9 & 3.3 \\
\hline & $\begin{array}{l}\text { Learning disorder } \\
\text { (LD) }\end{array}$ & 3 & 1.1 \\
\hline & Slow learner & 8 & 2.9 \\
\hline & $\begin{array}{l}\text { Intellectual } \\
\text { impairment }\end{array}$ & 13 & 4.8 \\
\hline & Total & 272 & 100.0 \\
\hline \multirow[t]{5}{*}{$\begin{array}{l}\text { Speech } \\
\text { therapists }\end{array}$} & $\begin{array}{l}\text { Autism spectrum } \\
\text { disorder (ASD) }\end{array}$ & 171 & 90.0 \\
\hline & $\begin{array}{l}\text { Global developmental } \\
\text { delay (GDD) }\end{array}$ & 12 & 6.3 \\
\hline & $\begin{array}{l}\text { Speech and } \\
\text { articulation disorder }\end{array}$ & 5 & 2.6 \\
\hline & Hearing impairment & 2 & 1.1 \\
\hline & Total & 190 & 100.0 \\
\hline \multirow{16}{*}{$\begin{array}{l}\text { Occupational } \\
\text { physiotherapists } \\
\text { and play } \\
\text { therapists (OT/ } \\
\text { PT) }\end{array}$} & $\begin{array}{l}\text { Attention deficit } \\
\text { hyperactivity (ADHD) }\end{array}$ & 8 & 3.7 \\
\hline & $\begin{array}{l}\text { Autism spectrum } \\
\text { disorder (ASD) }\end{array}$ & 126 & 58.9 \\
\hline & Cerebral palsy & 5 & 2.3 \\
\hline & Developmental delay & 26 & 12.1 \\
\hline & $\begin{array}{l}\text { Developmental } \\
\text { coordination disorder }\end{array}$ & 2 & 0.9 \\
\hline & Down's syndrome & 4 & 1.9 \\
\hline & Foot drop & 1 & 0.5 \\
\hline & $\begin{array}{l}\text { Global developmental } \\
\text { delay (GDD) }\end{array}$ & 24 & 11.2 \\
\hline & $\begin{array}{l}\text { Intellectual } \\
\text { impairment }\end{array}$ & 1 & 0.5 \\
\hline & Myelo meningocele & 2 & 0.9 \\
\hline & $\begin{array}{l}\text { Post-CVA writing } \\
\text { difficulty }\end{array}$ & 1 & 0.5 \\
\hline & Absent thumb & 1 & 0.5 \\
\hline & Hemiplegia & 2 & 0.9 \\
\hline & $\begin{array}{l}\text { Sensory processing } \\
\text { disorder }\end{array}$ & 1 & 0.5 \\
\hline & $\begin{array}{l}\text { Spinal muscular } \\
\text { atrophy }\end{array}$ & 10 & 4.7 \\
\hline & Total & 214 & 100.0 \\
\hline
\end{tabular}

used in the clinic to assess children between 6.6-11.5 years and between 11.6-16.5 years of age, respectively, for specific learning disorders $[9,10]$. These psychometric tests/assessments aim to help academically underachieving children with learning disabilities get help through classroom accommodations and modifications in school. Counseling for patients and parents/ family was done using cognitive behavior therapy, mindfulness techniques, and behavior modification therapy.

\section{DISCUSSION}

A significant number of the cases (362 patients, 55.6\%) attending the clinic were those with ASD, a developmental disability of public health importance affecting both child and family with direct and indirect cost implications for the nation in terms of health care, educational support, and rehabilitative services. A systematic review of four Indian studies demonstrated a relatively low prevalence estimate of ASD in the communitybased setting in India compared to the published international literature; with the study from the rural setting showed a pooled percentage prevalence of 0.1 in children aged $1-18$ years; and four studies conducted in the urban setting showed a pooled percentage prevalence of 0.09 in children aged $0-15$ years [11-15]. One of the studies in a population sample of schoolchildren in East India selected from various school types from three boroughs in Kolkata, showed the weighted prevalence estimates for broader autism spectrum to be $0.23 \%$ [15]. This lower estimate of ASD prevalence from the same geographical location as our study might be due to the reason that it excluded $\sim 20 \%$ of children from lower socioeconomic status who are outside the school system as well as the lower-functioning autistic children, who might not be going to any school at all. For better development of rehabilitative services, high-quality population-based epidemiological studies are urgently required to assess the exact burden of ASD in India.

Our study shows that a significant percentage $(55.3 \%)$ of children attending the clinic was aged $<5$ years. These data are in contrast with a previous study on the psychiatric morbidity pattern of children attending a CGC in the armed forces between 2001 and 2003 which showed a paucity of cases of children up to 3 years of age [16]. Moreover, this study did not report any case of autism. On contrary, in our study, a significant number of children aged below 5 years were presented with behavioral and developmental problems, with ASD being the most common (291 of 360 children; $80.8 \%$ ) problem in this age group ( $<5$ years). Our data are comparable with more recent data which suggest that ASD prevalence in India is as comparable to the global literature [2]. The data in our study may possibly be attributed to an increased awareness with earlier identification/referral of cases from the community. However, an actual rise in incidence of ASD in the country cannot be completely ruled out.

An earlier study [16] reported a male predominance which has been explained in terms of the attention and care given to the male children by the parents. Although our study also shows a similar predominance of males (487 of total 651 patients; $74.8 \%$ ), this male bias is possibly more due to the significantly larger number of boys presenting with ASD and ADHD. Data from other studies have shown that the prevalence of ASD is strongly male biased, on an average affecting 4 times as many males as females [17]. This is almost similar to the pattern of gender distribution we found in our study with male versus female ratio (M: F) being 3.6:1 in children with ASD. Studies have also shown that males are generally more likely to be diagnosed with ADHD than females, with $\mathrm{M}: \mathrm{F} \approx 4: 1$ in community [18]. Our data showed a similar pattern of gender distribution with $\mathrm{M}$ : $\mathrm{F}$ 
ratio being 4.2:1 in children with ADHD. In our study, behavioral issues were found to be more common in boys. Serious problems such as delinquency and oppositional defiant disorder were seen exclusively in boys. A meta-analysis on oppositional defiant disorder (ODD) during mid-childhood has shown the prevalence of ODD in boys [19], which is in corroboration with our finding. Intellectual impairment, learning disorder (LD), and slow learners are also significantly more common in boys as per our data. Boys were reported to be affected more often than girls by all the cognitive developmental pediatric disorders [20] including LDs [21], although explanation of gender differences could be due to several factors including referral bias [22]. Few cases of eating disorders and body image issues were seen exclusively in girls in our study.

Since our study population included outstation patients as well, it may be concluded therefore that for many of these children, it would be difficult to avail the regular interventional services at the clinic. This was further evidenced by the fact that only a third of the total number of patients were availing these services. Thus, there was a demand for such services that can be availed locally.

\section{CONCLUSION}

Recent data about the prevalence of behavioral and NDDs in Indian children in comparison with the previous studies show a changing pattern with increasing number of younger children now being identified. Multiple contributing factors include changing lifestyles and family dynamics with increasing urbanization. In contrast to earlier studies [16] but compatible with recent data [2], ASD, a developmental disorder of behavior and communication was identified in a significantly large numbers of children in our study. More evidence-based estimate of the population prevalence of ASD in India is needed to plan rehabilitative services.

\section{REFERENCES}

1. Executive Summary-NIPCCD (National Institute of Public Co-operation and Child Development); 2007. Available from: https://www.nipccd.nic.in/ file/reports/rclcgcr.pdf. [Last accessed on 2021 Jun 29].

2. Arora NK, Nair MK, Gulati S, Deshmukh V, Mohapatra A, Mishra D, et al. Neurodevelopmental disorders in children aged 2-9 years: Population-based burden estimates across five regions in India. PLoS Med 2018;15:e1002615.

3. Chlebowski C, Green JA, Barton ML, Fein D. Using the childhood autism rating scale to diagnose autism spectrum disorders. J Autism Dev Disord 2010;40:787-99.

4. Roopesh BN. Vineland social maturity scale: An update on administration and scoring. Indian J Clin Psychol 2020;46:91-102.

5. Purpura DJ, Lonigan CJ. Conners' Teacher Rating Scale for preschool children: A revised, brief, age-specific measure. J Clin Child Adolesc
Psychol 2009;38:263-72.

6. Styck KM, Watkins MW. Structural validity of the WISC-IV for students with learning disabilities. J Learn Disabil 2016;49:216-24.

7. Hidese S, Ota M, Matsuo J, Ishida I, Hiraishi M, Yokota Y, et al. Correlation between the Wechsler adult intelligence scale- $3^{\text {rd }}$ Edition metrics and brain structure in healthy individuals: A whole-brain magnetic resonance imaging study. Front Hum Neurosci 2020;14:21.

8. Koshy B, Mary TT, Samuel P, Sarkar R, Kendall S, Kang G. Seguin form board as an intelligence tool for young children in an Indian urban slum. Fam Med Community Health 2017;5:1-7.

9. Fawcett A, Nicolson R. The Dyslexia Screening Test: Junior (DST-J), Harcourt Assessment; 2004.

10. Rochelle KS, Talcott JB. Impaired balance in developmental dyslexia? A meta-analysis of the contending evidence. J Child Psychol Psychiatry 2006;47:1159-66.

11. Chauhan A, Sahu JK, Jaiswal N, Kumar K, Agarwal A, Kaur J, et al. Prevalence of autism spectrum disorder in Indian children: A systematic review and meta-analysis. Neurol India 2019;67:100-4.

12. Nair MK, Harikumaran Nair GS, Beena M, Princly P, Abhiram Chandran S, et al. CDC Kerala 16: Early detection of developmental delay/disability among children below 6 y-a district model. Indian J Pediatr 2014;81 Suppl 2:S151-5.

13. Raina SK, Kashyap V, Bhardwaj AK, Kumar D, Chander V. Prevalence of autism spectrum disorders among children (1-10 years of age)-findings of a mid-term report from Northwest India. J Postgrad Med 2015;61:243-6.

14. Poovathinal SA, Anitha A, Thomas R, Kaniamattam M, Melempatt N, Anilkumar A, et al. Prevalence of autism spectrum disorders in a semiurban community in South India. Ann Epidemiol 2016;26:663-5.

15. Rudra A, Belmonte MK, Soni PK, Banerjee S, Mukerji S, Chakrabarti B. Prevalence of autism spectrum disorder and autistic symptoms in a schoolbased cohort of children in Kolkata, India. Autism Res 2017;10:1597-605.

16. Chaudhury S, Prasad PL, Zacharias R, Madhusudan T, Saini R. Psychiatric morbidity pattern in a child guidance clinic. Med J Armed Forces India 2007;63:144-6.

17. Werling DM, Geschwind DH. Sex differences in autism spectrum disorders. Curr Opin Neurol 2013;26:146-53.

18. Ramtekkar UP, Reiersen AM, Todorov AA, Todd RD. Sex and age differences in attention-deficit/hyperactivity disorder symptoms and diagnoses: Implications for DSM-V and ICD-11. J Am Acad Child Adolesc Psychiatry 2010;49:217-28.e1-3.

19. Demmer DH, Hooley M, Sheen J, McGillivray JA, Lum JA. Sex differences in the prevalence of oppositional defiant disorder during middle childhood: A meta-analysis. J Abnorm Child Psychol 2017;45:313-35.

20. Nass RD. Sex differences in learning abilities and disabilities. Ann Dyslexia 1993;43:61-77

21. Rutter M, Caspi A, Fergusson D, Horwood LJ, Goodman R, Maughan B, et al. Sex differences in developmental reading disability: New findings from 4 epidemiological studies. JAMA 2004;291:2007-12.

22. Abdalah MQ. Gender difference in learning disabled children neuropsychological review. Res Rev Healthc Open Access J 2018;1:1-5.

Funding: None; Conflicts of Interest: None Stated.

How to cite this article: Khawash $\mathrm{P}$, Chatterjee A, Khawash A. A demographic study of patients with behavioral and neurodevelopmental disorders among children in East India. Indian J Child Health. 2021; 8(9):319-323. 